\title{
Ultrastructure of Calymmatobacterium granulomatis: comparison of culture with tissue biopsy specimens
}

\author{
A. B. M. KHARSANY, A. A. HOOSEN, T. NAICKER, P. KIEPIELA and A. W. STURM \\ MRC Genital Ulcer Disease Research Unit, Department of Medical Microbiology and Optics and Imaging \\ Centre, Faculty of Medicine, University of Natal, Durban, South Africa
}

\begin{abstract}
The ultrastructural features of cells of Calymmatobacterium granulomatis from monocyte co-cultures and tissue biopsy specimens were compared. In cultures the bacteria were mainly extracellular, i.e., not within membrane-bound vacuoles. The bacterial body was surrounded by a uniformly extensive homogeneous layer with a relatively high electron density. This layer varied considerably in tissue biopsy specimens, having either homogeneously electron-dense or delicate web-like structures with varying density and thickness. In tissue specimens the bacteria were located predominantly within vacuoles of varying sizes in the cytoplasm of the macrophages and, occasionally, extracellularly within the intercellular spaces of the stroma. The bacterial cytoplasm contained ribosomes scattered throughout with electron-dense granules located peripherally. The trilaminar cell-wall structure was typical of a gram-negative organism, comprising an outer membrane, a middle electron-opaque layer and an inner plasma membrane. Surface structures such as fimbriae, flagella and bacteriophages were not identified in specimens from either source.
\end{abstract}

\section{Introduction}

Calymmatobacterium granulomatis is the aetiological agent of granuloma inguinale (Donovanosis), a chronic granulomatous disease involving the genitalia and surrounding tissues. It has been recognised recently as a significant cause of genital ulcer disease in the KwaZulu/Natal region of South Africa [1-3].

Histological examination of granulation tissue from infected patients reveals the presence of macrophages, plasma cells, polymorphonuclear neutrophils and, occasionally, lymphocytes, multinucleated giant cells and dendritic cells [4-6]. The infected macrophages in the diseased tissue are highly activated, containing a variable number of bacteria within intracellular vacuoles. The observation of these intracellular bacteria is important for the diagnosis of the disease $[5,7]$.

C. granulomatis is not easily cultivable in vitro and, therefore, has been poorly studied. Previous studies on the ultrastructure of the organism have used infected

Received 4 Nov. 1997; revised version accepted 31 March 1998.

Corresponding author: Dr A. B. M. Kharsany. biopsy material fixed by procedures that were only adequate for the preservation of host tissue, but which did not satisfactorily preserve bacterial ultrastructure [8]. The ultrastructural characteristics of C. granulomatis has a trilaminar cell wall structure and is considered to be in accordance with its gram-negative staining. The cytoplasm is known to contain electron dense granules $[9,10]$. The bacteria have also been described as being surrounded by a clear layer (electron-lucent), the width of which varies considerably [6]. These have been described as capsules, but they appear to differ from those of other bacteria, which are invariably electron-dense [11]. The presence of bacteriophages either attached to the cell wall or as empty phage heads within the organism have been described $[4,7]$ or have been found to be absent $[5,6,9]$. The presence of pili (fimbriae) and vesicles evaginating from the cell membrane has been reported occasionally $[5,9,10]$. Therefore the ultrastructural characteristics of $C$. granulomatis are not clearly defined. Recently, the growth of C. granulomatis was achieved in a monocyte co-culture system and its presence was confirmed morphologically [12].

This study was undertaken to compare the ultrastructural features of $C$. granulomatis in tissue biopsy specimens with those observed in culture. 


\section{Materials and methods}

Monolayers of infected monocytes from three patients with granuloma inguinale were processed for transmission electron microscopy as described previously [12].

Tissue biopsy specimens of another three patients with a histologically confirmed diagnosis of granuloma inguinale were placed immediately in Karnovsky's fixative $(\mathrm{pH} 7.2)$ [13] for $1 \mathrm{~h}$ at $4^{\circ} \mathrm{C}$. The specimens were diced into $1-\mathrm{mm}$ cubes, then post-fixed in osmium tetroxide $1 \%$ in $0.2 \mathrm{M}$ sodium cacodylate buffer $(\mathrm{pH} 7.2)$ for $1 \mathrm{~h}$ at $4^{\circ} \mathrm{C}$, before dehydration through ascending grades of alcohol and embedding in Araldite epoxy resin. Ultra-thin sections $(50 \mathrm{~nm})$ were cut and double stained with uranyl acetate and Reynold's lead citrate [14] for 2 and $3 \mathrm{~min}$, respectively. Sections were viewed with a Jeol 100C transmission electron microscope.

\section{Results}

\section{Ultrastructure of C. granulomatis in monocyte co-} cultures

In the monocyte co-cultures, bacteria occurred extracellularly either singly or in clusters. The cytoplasm of these bacteria contained ribosomes and peripheral electron-dense granules. The cell wall was typical of a gram-negative organism, consisting of an outer membrane, a middle electron-opaque layer and an inner plasma membrane (Fig. 1). The capsule consisted of dense homogeneous material of relatively high electron contrast (Fig. 1). No surface structures suggestive of phage particles, fimbriae or flagella were identified. The bacteria were seen to divide by binary fission by pinching in of both the cell wall and periplasmic membrane.

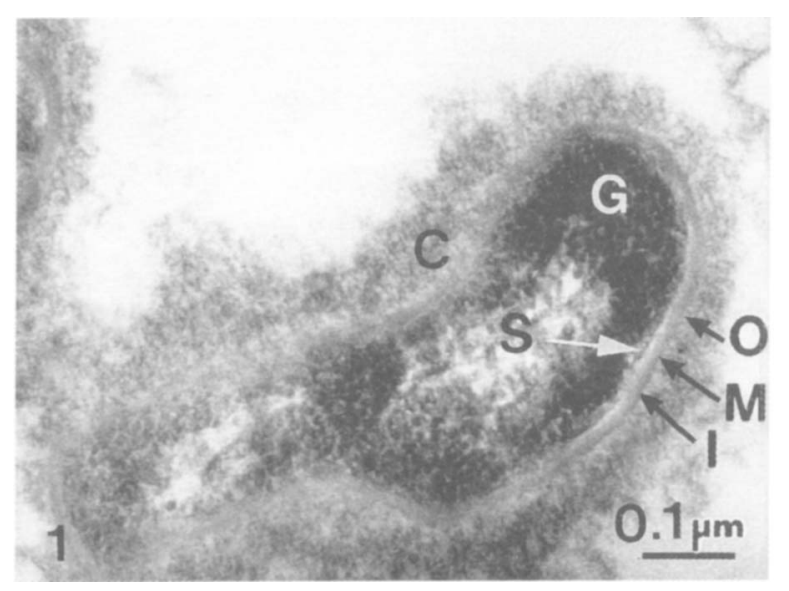

Fig. 1. Electron micrograph showing $C$. granulomatis in monocyte co-cultures with ribosomes, electron-dense granules $(\mathrm{G})$, trilaminar cell-wall structure consisting of outer membrane $(\mathrm{O})$, middle electron-opaque layer $(\mathrm{M})$ and an inner plasma membrane (I), periplasmic space (S) and a thick homogeneous electron-dense capsule (C).
Ultrastructure of C. granulomatis in tissue biopsy specimens

Epidermal layer. The epidermal layer consisted of keratinocytes that exhibited normal morphology, although moderate oedema was noted both intra- and inter-cellularly. Large polyhedral-shaped cells characteristic of stratum spinosum were observed. Adjacent cells were bound tightly by desmosomes which had normal dense plaque and filaments. Bundles of tonofilaments were abundant both intra- and intercellularly.

Dermal layer. The dermis was infiltrated with a rich inflammatory exudate consisting predominantly of large macrophages, plasma cells and neutrophils. The infected and non-infected macrophages had well-developed endoplasmic reticulum and Golgi apparatus. Mitochondria and lysosomes were abundant. The infected cells displayed varying stages of degeneration. Their nuclei were often displaced towards the periphery by a vacuole containing the bacteria. These vacuoles occupied a large part of the intracellular space. The number of ingested bacteria varied considerably from 3 to 20 /cell. Occasionally bacteria were found within vacuoles of necrotic neutrophils. In both the epidermis and dermis the bacteria occurred predominantly within macrophages and occasionally within the intercellular spaces. There was considerable variation in the morphological relationship of the phagocytic vacuole and the bacteria. The vacuoles occasionally had broken limiting membranes (Fig. 2a). Bacteria were also observed lying free in the cytoplasm within dense amorphous granular capsule-like material. The electron density of the capsular material was variable.

Morphological characteristics of bacteria (Donovan body). The shape and size of the bacteria in a single plane varied from round or oval to elliptical in shape. They measured $900 \mathrm{~nm}$ in width and $1700 \mathrm{~nm}$ in length. A filamentous skein of centrally located nucleoplasm was evident and the nuclear material consisted of fine chromatin threads. Electron-dense granules were prominent and located at the periphery of the cytoplasm, while ribosomes were scattered throughout the bacterial body (Fig. 2b). The cell wall consisted of an outer membrane, a middle electrondense layer and an inner plasma membrane (Fig. 2c). The periplasmic space was electron-lucent, and the outer surface of the cell wall was irregularly contoured. The width of the cell wall was $7 \mathrm{~nm}$, with the outer membrane measuring $2 \mathrm{~nm}$, the middle electron-opaque layer $4 \mathrm{~nm}$ and the inner plasrna membrane $1 \mathrm{~nm}$ (Fig. 2c).

The bacteria were encased by a well preserved homogeneous electron-dense capsule, varying between 40 and $150 \mathrm{~nm}$ in thickness. The width of these capsules was determined from the point where the capsular material was closely adherent to the bacterial 

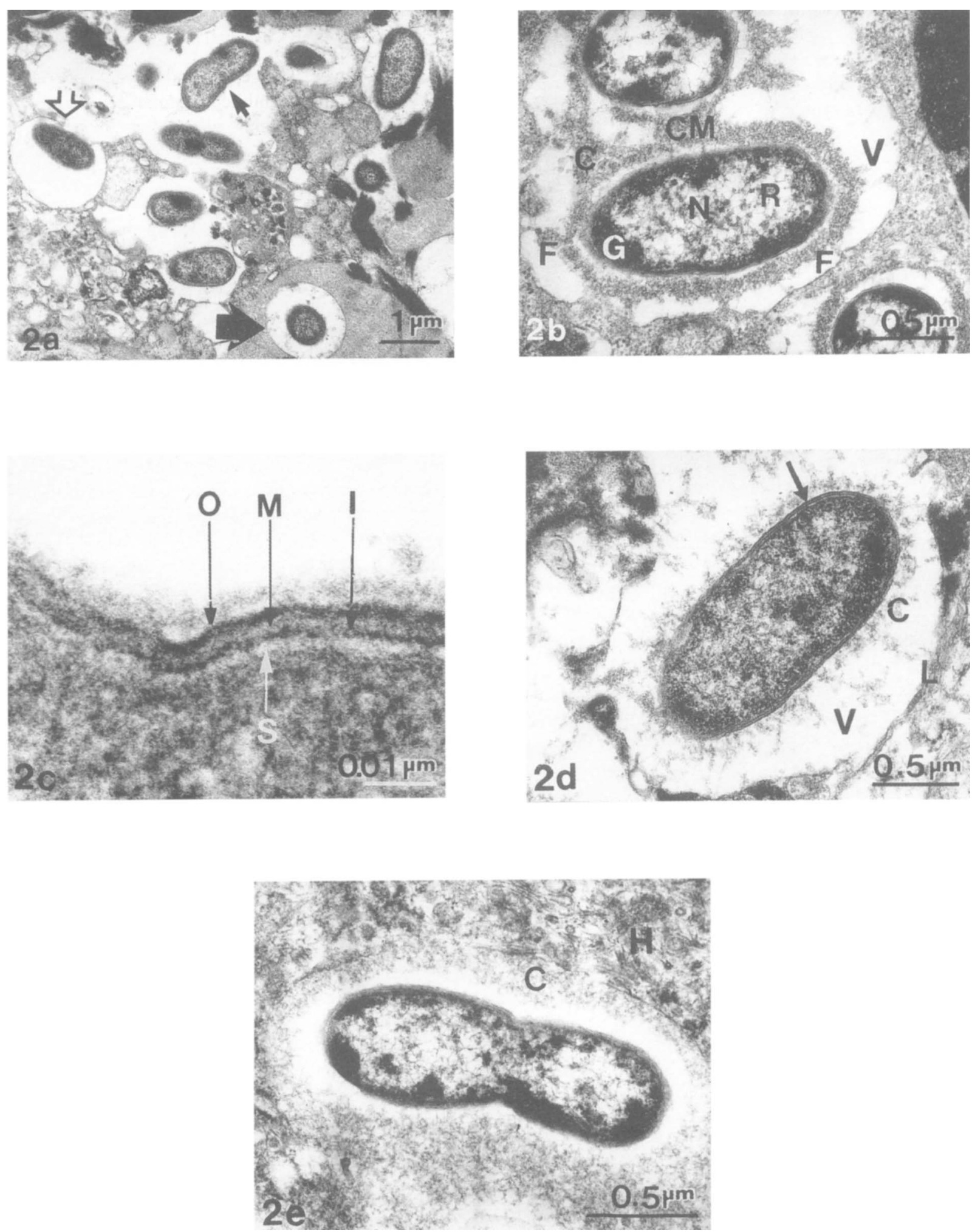

Fig. 2. Electron micrographs showing $C$. granulomatis in tissue biopsy specimens. a, infected degenerate cell. Note that bacilli occur within phagosomal vacuoles bound by a limiting membrane $(\uparrow)$ or a broken membrane ( $\uparrow$ ) with some bacilli $(\leftarrow)$ undergoing cell division. b, bacillus within a phagocytic vacuole (V). The filamentous nucleoplasm (N), electron-dense granules $(G)$, ribosomes $(R)$ and capsule $(C)$ are shown. Granules are peripherally positioned, while the nucleoplasm is centrally located. Capsular material $(\mathrm{CM})$ between adjacent bacilli continuous with each other can be seen. Fine fibrillar (F) strands are evident, attaching the capsule to the limiting membrane of the vacuole. c, cell-wall structure consisting of an outer membrane $(\mathrm{O})$, middle electron-opaque layer $(\mathrm{M})$, and inner plasma membrane (I), with periplasmic space (S). d, bacillus with a phagocytic vacuole (V) surrounded by a limiting membrane (L). The trilaminar cell-wall structure is evident (arrow). Note the fibrous nature of the capsule $(\mathrm{C})$. e, bacterium in the process of cell division within a phagosome. Note that the capsule $(C)$ has separated from the cell surface. The electron-dense area $(\mathrm{C})$ surrounding the clear area is being pushed to the periphery of the vacuole. Capsule (C) is distinct from the cellular cytoplasmic matrix $(\mathrm{H})$. 
body. The capsular material often appeared to merge with that from adjacent bacteria (Fig. 2b). A few bacteria showed an attachment of the capsular material to the inner surface of the limiting membrane of the phagocytic vacuole by fine fibrillar strands (Fig. 2b). The texture of the capsule of some bacteria was fibrous (Fig. 2d). Occasionally the capsule had separated from the cell wall, possibly because of preparation artifact (Fig. 2e). This showed the bacterial body to be surrounded by a clear area while the electron-dense area surrounding the clear area had been displaced and pushed to the periphery of the vacuole (Fig. 2e). The limiting membrane of the vacuole was clearly evident between the capsule and cellular matrix. There was no evidence of internal or external particles suggestive of phage-like entities or the presence of fimbriae or flagella.

Several bacteria were observed in the process of cell division within unfused or fused phagosomes. The bacteria were seen to divide into two daughter cells by the pinching inwards of the cell membrane and cell wall (Fig. 2a, c, e).

\section{Discussion}

The description of the ultrastructural features of $C$. granulomatis is controversial $[5,6,7,9,10]$. In the present study the ultrastructural morphological features of the organism in culture were similar to those observed in infected tissue biopsy specimens. In each case the presence of electron-dense granules towards the periphery of the cytoplasm, the typical gramnegative cell-wall structure and the electron-dense capsule layer surrounding the bacterial body were recognised.

The tissue response in granuloma inguinale was predominantly an accumulation of macrophages, plasma cells and neutrophils, while the presence of lymphocytes was rare. Non-infected cells displayed no evidence of necrosis, whereas infected cells were observed at various stages of degeneration. The mechanism by which $C$. granulomatis infects cells, persists within them and induces necrosis is unknown.

Electron-dense granules within the bacteria have been reported in previous studies $[4,6,7,9,10]$. Such granules are characteristically present in various species of bacteria as storage material - polymers of glucose - - in the form of glycogen and starch. Some bacteria store polyhydroxy butyrate in visible granules that usually disappear under restricted nutritional conditions, while others produce visible structures of an inorganic phosphate polymer. Such granules are prominent in cells of Corynebacterium diphtheriae. It may be possible that in Donovan bodies the intracellular electron-dense granules observed ultrastructurally and the characteristic intense single or bipolar staining appearance with the RapiDiff stain on light microscopy [12] are similar storage granules. The chemical nature of these granules needs to be determined.

The present results confirm the previous observations of the cell wall [5-9] as characteristically that of a gram-negative cell $[15,16]$. However, the presence of two membranes beneath the trilaminar cell wall as described by Chandra and Jain [10] was not observed.

This study demonstrates the presence of an electrondense capsule both in vivo and in vitro, confirming the results of other studies $[9,10]$. However, Kuberski et al. [6] described the capsule as being an electronlucent area and considered that it was 'presumably a capsule most probably representing capsular material', indicating that there was no clarity in the description of the capsule. Previous electron microscopic studies on granuloma inguinale have been performed on clinical biopsy specimens and these electron-lucent areas are compatible with the intracellular vacuoles seen in the present study. The true capsule might have been obscured, possibly because of inadequate specimen preservation $[8,17,18]$.

The composition of the $C$. granulomatis capsule, i.e., whether it is polysaccharide comprising single or multiple sugars or polypeptides has not been determined. The capsules of most other bacteria such as Haemophilus influenzae and Escherichia coli are polysaccharide and those of Bacillus anthracis and Yersinia spp. are polypeptide. All these capsules invariably have the same electron-dense character $[11,15,16]$ as that of $C$. granulomatis from both the monocyte co-cultures and biopsy specimens.

Dodson et al. [5] reported the presence of both capsulate and non-capsulate forms in biopsy specimens. Although an extensive search for non-capsulate forms was made, none were seen in the present study. However, some bacteria had narrow capsules, while others had extremely fine web-like structures. These forms may have been reported previously as noncapsulate forms.

Davis et al. [4,7] have described the presence of bacteriophages attached to the cell wall and empty phage heads within the organism and have proposed that $C$. granulomatis is infected with bacteria phages; however, this has been strongly refuted by others $[5,6]$ and the results of the present study. Furthermore, the present study provided no evidence of fimbriae of flagella.

In conclusion, this study confirms the similarity of the ultrastructure of $C$. granulomatis in monocyte cocultures and tissue biopsy specimens; the only observable difference being in the width and density of the capsule - which was enhanced in the former 
and variable for bacteria observed directly in tissue biopsy specimens.

This work was supported by grants from the University of Natal Research Fund and the Medical Research Council of South Africa.

\section{References}

1. Bassa AGH, Hoosen AA, Moodley J, Bramdev A. Granuloma inguinale (donovanosis) in women. An analysis of 61 cases from Durban, South Africa. Sex Transm Dis 1993; 20: $164-167$.

2. Hoosen AA, Mphatsoe M, Kharsany ABM, Moodley J, Bassa A, Bramdev A. Granuloma inguinale in association with pregnancy and HIV infection. Int J Gynaecol Obstet 1996; 53: $133-138$.

3. O'Farrell N. Trends in the reported cases of donovanosis in Durban, South Africa. Genitourin Med 1992; 68: 366-369.

4. Davis CM, Collins C. Granuloma inguinale: an ultrastructural study of Calymmatobacterium granulomatis. J Invest Dermatol 1969; 53: 315-321.

5. Dodson RF, Fritz GS, Hubler WR, Rudolph AH, Knox JM, Chu LW. Donovanosis: a morphologic study. J Invest Dermatol 1974; 62: 611-614.

6. Kuberski T, Papadimitriou JM, Phillips P. Ultrastructure of Calymmatobacterium granulomatis in lesions of granuloma inguinale. J Infect Dis 1980; 142: 744-749.

7. Davis CM. Granuloma inguinale. A clinical, histological and ultrastructural study. JAMA 1970; 211: 632-636.

8. Spagnolo DV, Coburn PR, Cream JJ, Azadian BS. Extragenital granuloma inguinale (Donovanosis) diagnosed in the United Kingdom: a clinical, histological, and electron microscopical study. J Clin Pathol 1984; 37: 945-949.

9. Chandra M, Jain AK, Ganguly DD, Sharma AK, Bhargava NC An ultrastructural study of Donovanosis. Indian $J$ Med Res 1989; 90: $158-164$.

10. Chandra M, Jain AK. Fine structure of Calymmatobacterium granulomatis with particular reference to the surface structures. Indian J Med Res 1991; 93: 225-231.

11. van Iterson W. Symposium on the fine structure and replication of bacteria and their parts. II Bacterial cytoplasm. Bacteriol Rev 1965; 29: 299-325.

12. Kharsany ABM, Hoosen AA, Kiepiela P, Naicker T, Sturm AW Growth and cultural characteristics of Calymmatobacterium granulomatis: the aetiological agent of granuloma inguinale (Donovanosis). J Med Microbiol 1997; 46: 579-585.

13. Karnovsky MJ. A formaldehyde-glutaraldehyde fixative of high osmolality for use in electron microscopy. J Cell Biol 1965; 27: $137 \mathrm{~A}-138 \mathrm{~A}$.

14. Reynold ES. The use of lead citrate at high $\mathrm{pH}$ as an electronopaque stain in electron microscopy. $J$ Cell Biol 1963; 17: 208-213.

15. Beveridge TJ, Graham LL. Surface layers of bacteria. Microbiol Rev 1991; 55: 684-705.

16. Costerton JW. The role of electron microscopy in the elucidation of bacterial structure and function. Annu Rev Microbiol 1979; 33: 459-479.

17. Silva MT, Sousa JCF. Ultrastructure of cell wall and cytoplasmic membrane of gram-negative bacteria with different fixation techniques. J Bacteriol 1973; 113: 953-962.

18. Silva MT, Macedo PM. Ultrastructure of Mycobacterium leprae and other acid-fast bacteria as influenced by fixation conditions. Ann Microbiol 1982; 133: 59-73. 